\title{
A hybrid process for 2,4-dichlorophenoxy acetic acid herbicidal treatment and its microbial identification by MALDI-TOF mass spectrometry
}

\author{
Gamze Dogdu Okcu ${ }^{a}$, Hatice Eser Okten ${ }^{b}$ and Arda Yalcuk ${ }^{a}$
}

${ }^{\mathrm{a} D e p a r t m e n t ~ o f ~ E n v i r o n m e n t a l ~ E n g i n e e r i n g, ~ A b a n t ~ I z z e t ~ B a y s a l ~ U n i v e r s i t y, ~ B o l u, ~ T u r k e y ; ~}{ }^{\mathrm{b}}$ Department of Environmental Engineering, Izmir Institute of Technology, Urla, Izmir, Turkey

ABSTRACT

The feasibility of coupling photocatalysis and a biological treatment to remove a herbicide - 2,4dichlorophenoxy acetic acid (2,4-D) - from pure water was examined using batch experiments following three protocols: aerated (A-BR) and non-aerated biodegradation (NA-BR) alone, and intimately combined photodegradation and biodegradation (P-B). In view of a subsequent biological treatment, 15 and $180 \mathrm{~min}$ irradiation times were chosen in accordance with spectrophotometric and LC-MS/MS results that indicated the decrease in the COD/TOC ratio during photocatalysis. Pre-treatment led to a quick decrease in concentration of 2,4-D and COD during the biological process: a $78.79 \pm 0.30 \%$ COD removal and $38.23 \pm 3.12 \%$ 2,4-D elimination was measured after $5760 \mathrm{~min}$ in A-BR, and $80.89 \pm 0.81 \%$ COD and $81.36 \pm 1.37 \%$ 2,4-D removal was achieved after $2880 \mathrm{~min}$ in P-B. For species identification using matrix-assisted laser desorption/ionization (MALDI)-time of flight (TOF)-TOF/MS equipment, Aeromonas eucrenophila, Stenotrophomonas acidaminiphila, Ralstonia pickettii, Sphingobacterium multivorum and Acinetobacter towneri were identified with high accuracy, and they play important roles in the degradation of 2,4-D.

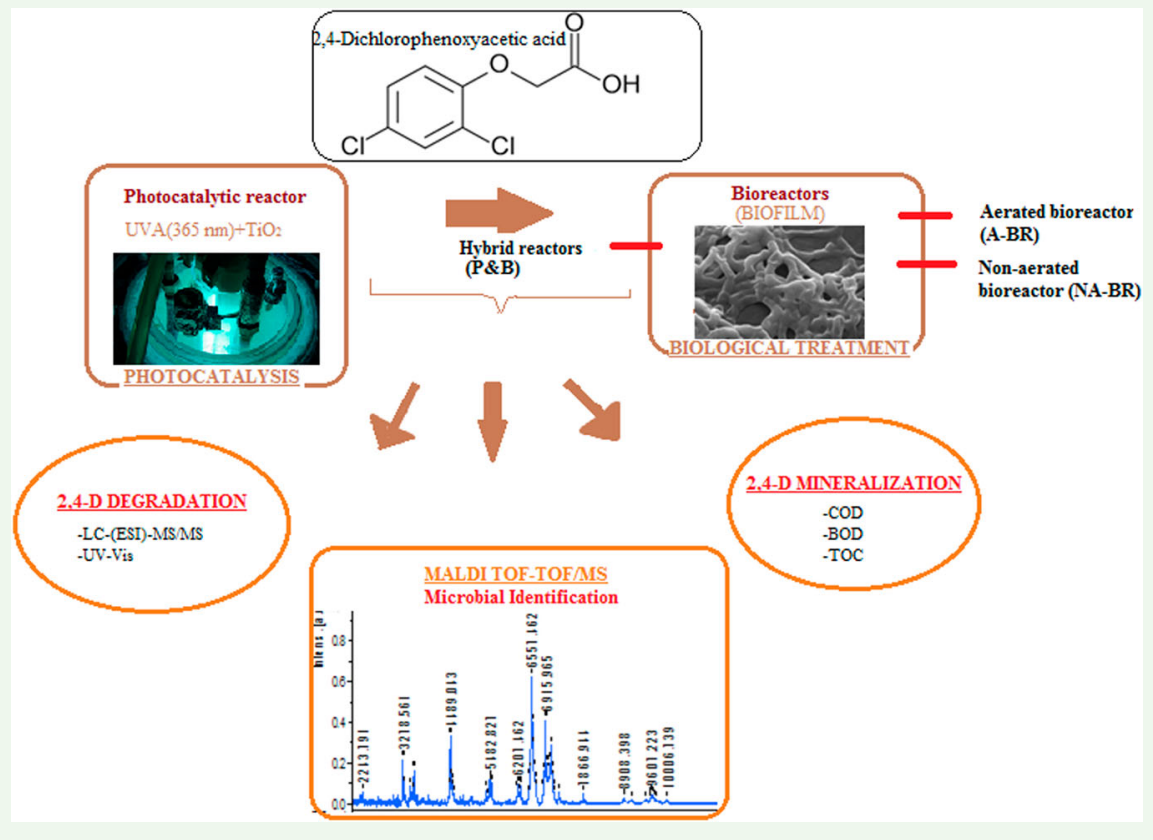

ARTICLE HISTORY

Received 8 May 2018

Accepted 5 August 2018

KEYWORDS

2,4-dichlorophenoxy acetic acid; biodegradability; biological treatment; photocatalysis; MALDI-TOFMS

\section{Introduction}

The last two decades have witnessed a sensational surge in concern about water and wastewater treatment as a way to protect water sources, the health of living beings and the environment, against the consequences of pesticide contamination [1]. In many regions of the world, and especially in Turkey, 2,4-dichlorophenoxy acetic acid (2,4-D) has been one of the most widely used chlorinated phenoxy-alkanoic herbicides, especially in potato, grain and corn production. It is used for

CONTACT Gamze Dogdu Okcu dogdu.gamze@gmail.com Department of Environmental Engineering, Abant Izzet Baysal University, 14030, Golkoy Campus, Bolu, Turkey

(-) Supplemental data for this article can be accessed at https://dx.doi.org/10.1080/09593330.2018.1510433.

○ 2018 Informa UK Limited, trading as Taylor \& Francis Group 
controlling broad-leaf weeds in a variety of agricultural activities and gardening due to its high efficiency and low cost [2]. 2,4-D is considered moderately toxic (class II) by the World Health Organization (WHO), and its carcinogenicity, neurotoxicity and endocrine disruptive potential cannot be neglected [2,3]. Since this compound is mostly degraded to the anionic form, which exhibits high water solubility $\left(667 \mathrm{mg} \mathrm{L}^{-1}\right)$, high mobility and is long lasting, its continuous use may cause soil percolation, and surface and groundwater contaminations. Moreover, $2,4-D$ is often detected in surface $\left(\approx 6 \mu \mathrm{g} \mathrm{L}^{-1}\right)$ and drinking water $\left(2.2-3.2 \mu \mathrm{g} \mathrm{L}^{-1}\right)$ sources [4]. The half-life of 2,4-D in the environment is relatively short, averaging 10 days (1-6 weeks) due to its susceptibility to biological treatment in soils [5] and less than 10 days in water. The regulatory standard for 2,4-D in drinking water is 0.1 and $70 \mu \mathrm{g} \mathrm{L}^{-1}$ as per the Turkish standard [6] and the U.S. standard [7], respectively.

The main problem is that it is not feasible to treat water polluted with pesticides with classical biological treatment methods, especially those based on pure strains of bacteria. The toxicity of the microorganisms involved in these processes, the long treatment time and the presence of halogens in the molecular structure of 2,4-D that renders it highly persistent and resistant to biodegradation $[8,9]$. The most recent studies - including this study - conducted on biodegradation used microbial mixtures without using a pure culture to imitate realistic conditions and maintain microbial activities over a wider range of conditions that could affect the rate of biodegradation $[8,10]$. Moreover, because of the biorefractory nature of chlorophenoxy herbicides, a great deal of attention has been given to the extension, development and advancement of innovative approaches, ideas or designs. These innovative developments focus on enhancing the efficiency of well-known technologies - or combining them with sustainable, cheaper environmentally friendly treatment methods to reduce costs or eliminate other disadvantages [11]. In recent years, by producing ${ }^{*} \mathrm{OH}$ radicals through chemical, photochemical, photocatalytic and electrochemical reactions, advanced oxidation processes (AOPs) have become a promising technology to eliminate pesticides from water systems [1]. Unfortunately, the AOPs like photocatalysis - are limited due to the high cost and energy required to run the process and to achieve complete mineralization. In addition, these processes can produce more toxic and/or bio-recalcitrant intermediate products, and there is a lack of knowledge on the process design and operation of large-scale reactors based on this principle $[9,12]$. Recently, in order to degrade recalcitrant compounds, reduce the toxicity, treatment time and economic/energy costs, employing
AOPs as a pre-treatment method in combination with biological treatment has been recommended $[13,14]$. The most common arrangement is pre-treatment with AOPs to degrade pollutants to make them more easily converted and oxidized through biodegradable methods. Biological processes are then used as a second step to complete mineralization and oxidation of intermediate products [15]. This combination model is beneficial in order to protect microorganisms from UV irradiation and hydroxyl free radicals during photocatalysis.

In published scientific literature, there are a limited number of reports the potential of coupled photocatalytic-biological treatment $[8,12,15-17]$. However, this is the first comprehensive study on the hybrid treatment of 2,4-D herbicide using a mixed-culture biofilm system and the detailed identification of bacterial isolates for all the biological systems. Matrix-assisted laser desorption/ionization, time of flight, mass spectrometry (MALDI-TOF/MS) is a method for determining the genus, species and even sub-species of bacterial isolates for the technique, chosen because of its basic sample preparation steps, low financial cost per analysis and rapid acquisition time [18]. In this work, firstly, the optimal time ratio was determined for the hybrid process by assessing degradation, oxidation and mineralization results of the 2,4-D; then the biodegradability of the residual 2,4-D solution was evaluated. Secondly, residual 2,4-D concentrations and chemical oxygen demand (COD) were analysed in three batch modeoperated biological reactors: aerated (A-BR), nonaerated (NA-BR) and hybrid reactors (P-B). Finally, MALDI-TOF-TOF/MS techniques were used to evaluate the impacts of 3 different bioreactors for 2,4-D degradation on the community structure before and after the biodegradation.

\section{Materials and methods}

\subsection{Chemicals}

All chemicals used in the investigation were used without further purification. Titanium (IV) oxide nano powder (AEROXIDE ${ }^{\circledR}$ P25 $\geq 99.5 \%, 21 \mathrm{~nm}, 35-65 \mathrm{~m}^{2} \mathrm{~g}^{-1}$ (BET)) was used as a photocatalyst (Sigma Aldrich) due to its high performance and availability in photocatalytic degradation reactions. Commercial grade Amin EXT 500 $\mathrm{SL}$ (equivalent to $500 \mathrm{~g} \mathrm{~L}^{-1}$ of 2,4-D) 2,4-D amine salt $\left(\mathrm{C}_{10} \mathrm{H}_{13} \mathrm{Cl}_{2} \mathrm{NO}_{3}, \mathrm{MW}: 266.12 \mathrm{~g} \mathrm{~mol}^{-1}\right)$ was supplied by the Agrofarm $^{\oplus}$ Company. Plate Count Agar (PCA) was obtained from Merck (Germany) as a solid medium for microbial cultivation. Other chemicals: $\mathrm{NaOH}, \mathrm{H}_{2} \mathrm{SO}_{4}$ (essay 97\%), $\mathrm{NH}_{4} \mathrm{Cl}, \mathrm{CaCl}_{2} \cdot 2 \mathrm{H}_{2} \mathrm{O}, \mathrm{FeCl}_{3}, \mathrm{MgSO}_{4} \cdot 7 \mathrm{H}_{2} \mathrm{O}$, 
$\mathrm{MnCl}_{2} \cdot 4 \mathrm{H}_{2} \mathrm{O}$ and $\mathrm{Na}_{2} \mathrm{MoO}_{4}$ were obtained from Merck (Germany). All chemicals employed were used without further treatment. All solutions and reaction mixtures were prepared with purified water (Merck Millipore, spec. resistivity: $18.2 \mathrm{M} \Omega \mathrm{cm}$ ).

\subsection{Photocatalytic set-up}

Photocatalytic experiments were performed in a $4.6 \mathrm{~L}$ (operating volume: $1 \mathrm{~L})$ cylindrical, $(14 \mathrm{~cm} \mathrm{D} \times 30 \mathrm{~cm} \mathrm{~L})$ batch photoreactor maintained at $22 \pm 1^{\circ} \mathrm{C}$. The photoreactor was constructed from three parts: (i) an exterior Pyrex glass; (ii) a Pyrex glass thimble, with the head part fitted to the outside container to form a gastight seal so that running water can be passed through the thimble to cool the reaction solution and (iii) an empty quartz chamber in which a Philips PL-L UVA 36 W lamp (315-380 nm; $110 \mu \mathrm{W} \mathrm{cm}{ }^{2}$ ) was placed. The reactor was also equipped with a control system, a water level sensor system, and water inlet-outlet and gas inlet opening to supply air from a diffuser system with a capacity of $3.5 \mathrm{~L} \mathrm{~min}^{-1}$ during the experiments. The reactor was wrapped with aluminium foil to prevent UV ray penetration. For irradiation experiments, the desired 2,4-D concentration was diluted from a $100 \mathrm{mg} \mathrm{L}^{-1}$ stock solution in amber-glass vessels and they were prepared daily. The system was stirred and aerated in order to increase the oxygen transfer to the solution following the addition of the $\mathrm{TiO}_{2}$ for at least $30 \mathrm{~min}$ in the dark and allow the system to reach equilibrium in case of adsorption. This time was determined so that, under stirring in the dark, no more herbicide molecules could be adsorbed by the photocatalyst. The UV light was turned on to irradiate the solution and the first sample was taken $(t=0)$. The photo-oxidized solution was filtered using Merck Millipore filters $(0.45 \mu \mathrm{m})$. The photocatalytic experiments were repeated three times to check the reproducibility of the experimental results. The mineralization experiments were performed in duplicate for $1440 \mathrm{~min}$.

\subsection{Biological set-up}

The set of biodegradation experiments were conducted in a FerMac 200 (working volume: $500 \mathrm{~mL}$; $205 \times$ $390 \mathrm{~mm}$ ) batch bioreactor, and a $3 \mathrm{~L}$ beaker was used as the second parallel batch bioreactor. The bioreactors contained $100 \mathrm{~mL}$ of 2,4-D herbicide and $400 \mathrm{~mL}$ of bacterial medium (BM-2,4-D medium, equal in total to $50 \mathrm{mg} \mathrm{L}^{-1}$ of 2,4-D herbicide). The biodegradation experiments were performed in duplicate. An aerated bioreactor (A-BR) and hybrid reactors ( $\mathrm{P}-\mathrm{B})$ were stirred at $150 \mathrm{rpm}$ and air bubbled through them at a rate of
3.5 $\mathrm{L} \mathrm{min}^{-1}$ during the experiments by using two separate magnetic stirrers (Rocker HP 220, Heidolph MR-Hei standard D-91126), an air pump (Hailea Aco 6603) and a diffusor to saturate the water with oxygen. In addition, a digital thermometer was used to continuously monitor the temperature in the reactors to keep it constant at 24 $\pm 1^{\circ} \mathrm{C}$. Three protocols were employed i.e. photocatalysis alone, aerated and non-aerated biodegradation (A-BR, $N A-B R$ ), and hybrid reactors (P-B), to evaluate 2,4-D degradation in batch experiments.

\subsection{Bacterial medium}

The bacterial medium consisted of $3.6 \mathrm{mM}$ of $\mathrm{NH}_{4} \mathrm{Cl}, 45.0$ $\mu \mathrm{M}$ of $\mathrm{CaCl}_{2} \cdot 2 \mathrm{H}_{2} \mathrm{O}, 0.6 \mu \mathrm{M}$ of $\mathrm{FeCl}_{3}, 4.2 \mu \mathrm{M}$ of $\mathrm{MgSO}_{4} \cdot 7 \mathrm{H}_{2-}$ $\mathrm{O}, 1.6 \mu \mathrm{M}$ of $\mathrm{MnCl}_{2} \cdot 4 \mathrm{H}_{2} \mathrm{O}$ and $24.3 \mathrm{nM}$ of $\mathrm{Na}_{2} \mathrm{MoO}_{4}$ (Merck, Germany) in MilliQ (Millipore, Merck) water [17]. After the $\mathrm{pH}$ of the medium was adjusted to a range from 7.0 to 7.2 with $1 \mathrm{M}$ of phosphate buffer, the nutrient solution was autoclaved and cooled for $15 \mathrm{~min}$ at $121^{\circ} \mathrm{C}$.

\subsection{Inoculum}

Activated sludge was obtained from a secondary clarifier sewage treatment plant in Bolu, Turkey, and frozen in 15 $\mathrm{mL}$ aliquots at $-20^{\circ} \mathrm{C}$ in a 1:1 mixture of activated sludge and $50 \%$ glycerol $(\mathrm{v} / \mathrm{v})$. Prior to the reactor inoculation, the aliquot was thawed, centrifuged at $5000 \mathrm{rpm}$ for $5 \mathrm{~min}$, and $15 \mathrm{~mL}$ of the supernatant was decanted and replaced with fresh bacterial medium. This washing process was repeated three times to remove the glycerol from the inoculum.

\subsection{Analytical methods}

COD was measured by using COD test kits (Test Kits No: 1.14541 from Merck, Germany) with a UV spectrophotometer (Pharo 100). A $3 \mathrm{~mL}$ sample was measured after treatment for $120 \mathrm{~min}$ at $150^{\circ} \mathrm{C}$ in the thermoreactor (Merck Spectroquant TR 320). Total organic carbon (TOC) was analysed with a Shimadzu TOC-L using the NPOC method $\left(680^{\circ} \mathrm{C}, 150 \mathrm{~mL} \mathrm{~min}{ }^{-1}\right.$, with an injection volume of $20 \mathrm{ml}$, a spray gas flow of $80 \mathrm{ml}$, and a spray time of $1.30 \mathrm{~min}$ ). The $\mathrm{pH}$ and temperature measurements of all samples from the photocatalytic reactor were measured using a pH meter (Orion Star A329 Thermo Scientific) and a pH probe (8107UWMMD ROSS $\mathrm{pH} /$ temperature electrode). A Liquid ChromatographyMass Spectrometry-Electrospray lonization instrument was used (Thermo TSQ Quantum Access Max LC-(ESI)$\mathrm{MS} / \mathrm{MS}$ ) to verify the degradation of the 2,4-D into intermediate products, to identify the metabolites and to determine the residual herbicide concentration using 
the AOAC Official Method 2007.01 (Mobile phase A: 5 $\mathrm{mM}$ of ammonium formate, $0.1 \%$ of formic acid (95:5 Water:MeOH) and Mobile phase B: $5 \mathrm{mM}$ of ammonium formate, $0.1 \%$ of formic acid (5:95 Water: $\mathrm{MeOH})$ ). SEM (Scanning Electron Microscopy) images were taken to observe the biofilm formation in the bioreactor systems. SEM analyses were performed using FEI Quanta FEG 250 Scanning Electron Microscopy. Microorganism species formed and disappearing at the entry and exit of the bioreactor was determined by placing them in AutoFlex MALDI-TOF-TOF-MS (Bruker) using BioTyper (Version 3.1) software and a reference database (in positive linear mode with a laser frequency of $50 \mathrm{~Hz}$ ). MS signals were obtained using the manufacturer's automated method - MBT_FC.par - for each sample in the positive linear mode and from the 2 to $20 \mathrm{kDa} \mathrm{m} / \mathrm{z}$ range.

\subsection{Matrix-assisted laser desorption/ionization time of flight mass spectrometry (MALDI-TOF-MS) profile acquisition and bacterial identification}

Firstly, to prepare samples by the direct transfer (DT) method, the biological material (single colony) was directly applied as a thin film on a MALDI spot plate taken from an aqueous PCA petri dish that was pre-incubated overnight. HCCA (a-cyano-4-hydroxycinnamic acid) was used as a matrix, and a composition of $50 \%$ acetonitrile, $47.5 \%$ water and $2.5 \%$ trifluoroacetic acid was used as a standard solvent. One $\mu \mathrm{L}$ of HCCA matrix solution was coated onto the biological material. The spotted layers were left to dry at RT. Subsequently, the target layer was loaded onto a MALDI-TOF/TOF-MS instrument and the mass spectrum was automatically formed from the samples and then analysed using an AutoFlex mass spectrometer connected to the MALDI instrument. For isolates with scores less than 2.0 - after the DT method was applied - the in situ ethanol/formic acid extraction method was then applied to the layer [19].

MALDI-TOF/TOF-MS profiles taken from bacteria isolates were matched with reference MALDI-TOF/TOFMS and the Log (score) and related colour code (green, yellow and red) was indicated by the BioTyper. If the Log score was higher than the green colour code, it indicated a high probability description of the species level. If the Log score was between 2.0 and 2.3 (green), it indicated a high probability description at a kind level. If the Log (score) was between 1.7 and 2.0 (yellow), it indicated only a probable kind description, while if the score is less than 1.7 (red), it means that there was no significant similarity between the unknown profile and any of the database. Moreover, consistency categories A, B and C are assigned to descriptions by the Biotyper software that is based on analysing the ten best matches. For category
$A$, in the species consistency, the best match was classified as green by MALDI (species description). For category $B$, in the kind consistency, the best match was classified as green or yellow. In this category, the conditions for species consistency were not fulfilled. For category C, there was no consistency for either species or kind [20].

\section{Results and discussion}

\subsection{Photocatalytic mineralization performance of 2,4-D herbicide}

Before considering the coupling of photocatalysis and biological treatment, optimization studies were conducted spectrophotometrically for governing parameters such as $\mathrm{pH}(3,5,7,9), \mathrm{TiO}_{2}$ concentration $\left(0,0.5,1,1.5,2 \mathrm{~g} \mathrm{~L}^{-1}\right)$, initial herbicide concentration $\left(10,25,50,100 \mathrm{mg} \mathrm{L}^{-1}\right)$ and $\mathrm{H}_{2} \mathrm{O}_{2}$ concentration $\left(50,100,150,200 \mathrm{mg} \mathrm{L}^{-1}\right)$. The maximum removal efficiency was achieved for an initial $25 \mathrm{mg} \mathrm{L}^{-1}$ 2,4-D herbicide concentration at a pH of 5, using $1.5 \mathrm{~g} \mathrm{~L}^{-1}$ of $\mathrm{TiO}_{2}$ and $150 \mathrm{mg} \mathrm{L}^{-1}$ of $\mathrm{H}_{2} \mathrm{O}_{2}$ (data not shown). Spectrophotometric measurements indicated that 15 min of photocatalysis produced the most degraded mixture of products (data not shown). However, the rise that was observed following 15 min gave us every reason to suspect that interference had been occurring. So, in the first step, by using optimal degradation parameters, photocatalytic oxidation experiments were carried out until total 2,4-D elimination by LC-MS/MS - and its total mineralization - in order to get information on the kinetics (Figure 1). The mineralization performance and biodegradability of the photocatalytic treatment of 2,4-D herbicide was constructed as the first stage of a hybrid process in which effluent from the photocatalysis reactor would be fed to the biological reactor for further treatment. The relationship between the photodegradation efficiency of 2,4-D with illumination time was investigated by fixing the $\mathrm{pH}$ at 5, using an initial herbicide concentration of 25 $\mathrm{mg} \mathrm{L}^{-1}$ and a catalyst concentration of $1.5 \mathrm{~g} \mathrm{~L}^{-1}$ of P25 $\mathrm{TiO}_{2}$. All mineralization studies were completed within 1440 min but they were limited to $200 \mathrm{~min}$ to obtain a better image in the graphs. LC-MS/MS analyses confirmed a degradation efficiency of $97.47 \pm 0.27 \%$ for 2,4-D after $60 \mathrm{~min}$ (Figure 1). Djebbar et al. [21] stated that at a pH of 4.2 , and $5.10^{-4} \mathrm{M}$ of $2,4-\mathrm{D}$ was rapidly degraded in approximately $100 \mathrm{~min}$. The oxidizing power of the $\mathrm{OH}^{*}$ radicals that were generated during photocatalysis was known to be strong enough to completely oxidize 2,4-D to $\mathrm{CO}_{2}, \mathrm{H}_{2} \mathrm{O}$ and other mineral acids [22]. As shown in Figure 1, the increase in 2,4-D photodegradation was only $5 \%$ from 60 to $180 \mathrm{~min}$. The probable reason could be that, when the irradiation time increased, a large number of small organic molecules were produced and adsorbed 


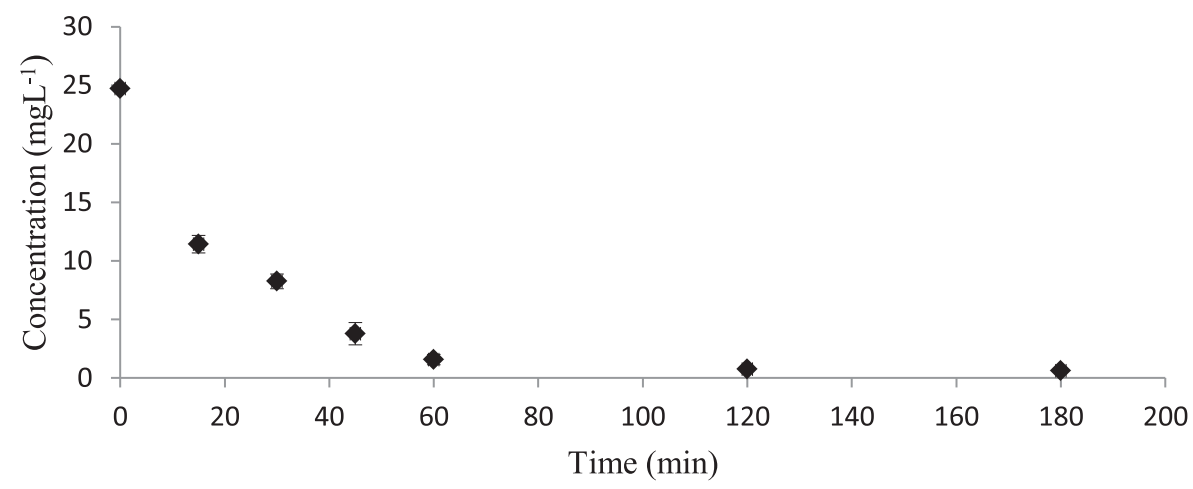

Figure 1. Time-dependent measurements of 2,4-D concentration during the photocatalytic degradation of $2,4-\mathrm{D}\left(C_{o}=25 \mathrm{mg} \mathrm{L}^{-1}\right)$.

onto the surface of the $\mathrm{TiO}_{2}$ resulting in decreased formation of $\mathrm{OH}^{\cdot}$ radicals that could attack the 2,4-D molecules [22].

Mineralization was investigated through measuring COD and TOC. Decreases in COD during irradiation indicated that 2,4-D was transformed into intermediate products by photo-oxidation, $\mathrm{CO}_{2}$ and $\mathrm{H}_{2} \mathrm{O}$ as the reaction progressed [23]. Approximately $53.04 \pm 3.14 \%$ of the TOC decrease was obtained at the end of $1440 \mathrm{~min}$ photocatalytic experiment. The lowest COD concentration obtained was $20 \pm 2.83 \mathrm{mg} \mathrm{L}^{-1}$ at $180 \mathrm{~min}$, which also corresponded to a TOC concentration of $13.56 \pm 0.77 \mathrm{mg} \mathrm{L}^{-1}$ (Figure 2). Based on the repetitive experiments, the maximum COD removal was obtained at 180 min then stabilized that was thought depending on the excess oxygen required by the intermediates formed after this time (Figure 2). After $180 \mathrm{~min}, \mathrm{COD}$ concentration was $65.52 \pm 3.88 \%$ of the initial concentration, indicating significant residual organic content. This was also confirmed by the TOC profile. At the end of $1440 \mathrm{~min}$, although $53.04 \pm 3.14 \%$ of the initial carbon amount in 2,4-D could be transformed into $\mathrm{CO}_{2}$, photocatalytic mineralization of 2,4-D was completed (Figure 1). This phenomenon can be attributed to the formation of organic intermediates during the period between the degradation of the first molecule and total mineralization. In this study, after degradation of 2,4-Dicholorophenoxy acetic acid $(m / z=221.0)$ with $\mathrm{TiO}_{2} / \mathrm{UV}$, the products formed were 2,4-dichlorophenol (2,4-DCP) $(\mathrm{m} / \mathrm{z} 163.0)$ in high amounts, 2,4-dichloro-1-methoxy benzene (2,4DCA) $(\mathrm{m} / \mathrm{z}=176.0)$ and 4-chlorophenol (4-CP) $(\mathrm{m} / \mathrm{z}=$ 128.50) in low amounts. Singh and Muneer [24] obtained many intermediates by analysing 2,4-D with GC/MS in the presence of a P25 catalyst: 2,4-dichlorophenol (2,4-DCP), 2,4-dichloro-1-methoxy benzene, benzaldehyde, benzyl alcohol, 3,5-dichlorobenzene-1,2-diol, 4-chlorophenol (4-CP), 4-6-dichlorobenzene-1,3-diol and 3-chlorobenzene-1,2-diol. They indicated that 2,4-dichlorophenol formed as a result of bonding ${ }^{-} \mathrm{OH}$ radicals to the alkyl chain in the molecule and it was the first basic intermediate of 2,4-D. Longer irradiation times were necessary to perform complete mineralization under the given experimental conditions [25].

Biodegradability of photocatalysis products becomes important for the biological stage that will following the current study. Therefore, an increase in oxidation of the target compound (COD decrease) with limited mineralization (low TOC decrease) is a favourable trend to

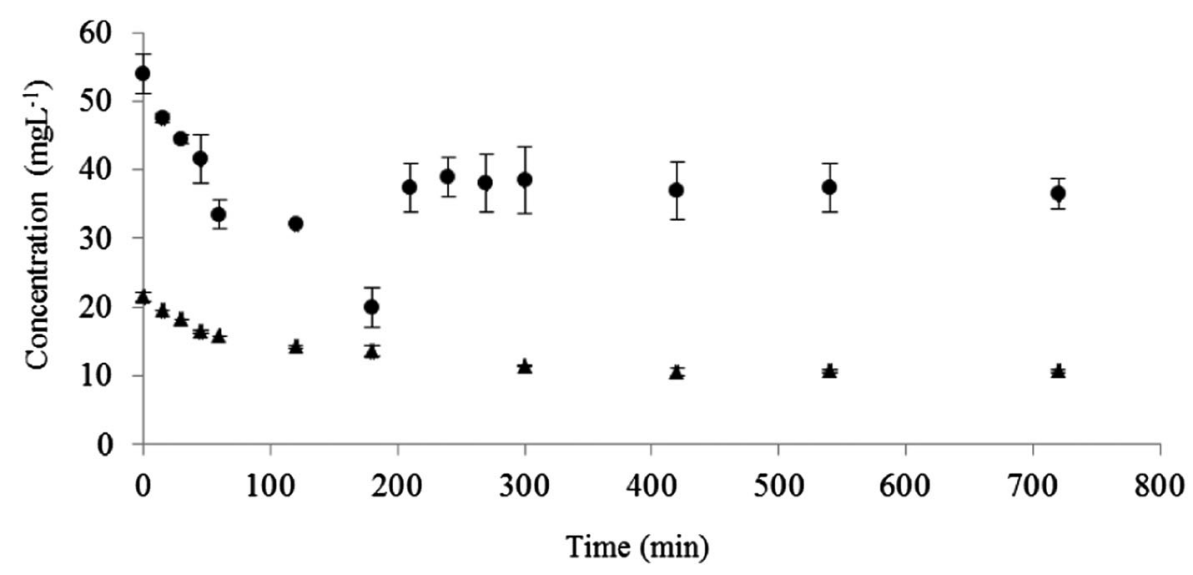

Figure 2. Time-dependent measurement of $\operatorname{COD}(\mathbf{O})$ and TOC $(\mathbf{\Delta})$ during the photocatalytic degradation of $2,4-\mathrm{D}\left(C_{o}=25 \mathrm{mg} \mathrm{L}^{-1}\right)$. 
understand the significant residual organic compounds for microbial cultures [16]. Finally, a favourable trend is a decrease in the ratio of COD/TOC during the photocatalytic degradation of the target compound, in other words, 2,4-D herbicide (Figure 2). COD removal was a maximum where the majority of 2,4-D was eliminated and then afterwards the COD value increased and was stable, probably due to the formation of stable by-products. According to Bouafia-Chergui et al. [26] the reason for incomplete removal of COD is the formation of toxic byproducts due to the photocatalytic treatment. Since the second stage of this study was going to be a biological treatment, oxidizable organic content was important to investigate. As shown in Figure 2, COD and TOC experiments have pointed out that at $180 \mathrm{~min}$ the COD/TOC ratio reached a minimum. We concluded that two time points, one determined spectrophotometrically $(15 \mathrm{~min})$ during the optimization studies of batch mode photocatalytic experiments and the other determined through measuring COD/TOC (180 min), might produce two different and possibly favourable influents for the biological treatment. From LC-MS/MS measurements we knew that the effluent after 15 min would have $11.43 \pm 0.75 \mathrm{mg} \mathrm{L}^{-1}$ of 2,4-D, (Figure 1) yet the spectrophotometer measured a minimum for every optimization experiment. The COD/TOC ratio was a minimum at $180 \mathrm{~min}$ indicating the maximum degree of reduction for carbon compounds in the system. Since $180 \mathrm{~min}$ would clearly provide a more biologically favourable photocatalytic effluent, 15 min produced a more energetically favourable (less irradiation time) photocatalytic effluent.

\subsection{Biodegradability performance of $2,4-D$ herbicide}

The biodegradation of process effluent from the 2,4-D solution with an initial concentration of $25 \mathrm{mg} \mathrm{L}^{-1}$ at 15 and $180 \mathrm{~min}$ - processed by the photocatalytic treatment - is determined by the $\mathrm{BOD}_{5} / \mathrm{COD}$ ratio. At the beginning, the biodegradation index $\left(\mathrm{BOD}_{5} / \mathrm{COD}\right)$ ratio $\approx 0$ while the $\mathrm{BOD}_{5} / \mathrm{COD}$ ratio of the process effluent at $15 \mathrm{~min}$ was 0.1 , and the $\mathrm{BOD}_{5} / \mathrm{COD}$ ratio of the process effluent at 180 min was 0.20 . Accordingly, because the $\mathrm{BOD}_{5} / \mathrm{COD}$ ratio was less than 0.4 , it was shown that the photocatalysis solution was poorly suited to biological degradation [27]. Fontmorin et al. [28] stated that the $\mathrm{BOD}_{5} / \mathrm{COD}$ ratio was 0.04 before the analysis while it increased to 0.25 after electrocatalysis, indicating a significant increase in the biodegradability of the waste, and while this phenomenon cannot obtain the biodegradability limit, further biological treatment can be promising. In the study, it was considered that the presence of a similar commercial dimethylamine salt could increase general biodegradability. At the end of $180 \mathrm{~min}$, although biodegradation increased in low amounts due to irradiation, it could not reach the limit of degradability. As seen in the COD mineralization graph in Figure 2, it was determined that COD decreased from $65.52 \%$ to $35.34 \%$, depending on the formation of stable intermediates after $180 \mathrm{~min}$. It is thought that a microorganism community accustomed to the environment can increase COD mineralization after $180 \mathrm{~min}$. Therefore, although biodegradability of the 2,4-D solution obtained from the photocatalytic process is low, this phenomenon also indicates that the mineralization change of this pollutant should be examined with a mixed microorganism culture accustomed to 2,4-D herbicide at a concentration of $25 \mathrm{mg} \mathrm{L}^{-1}$. The COD value was $20 \pm 2.83 \mathrm{mg} \mathrm{L}^{-1}$ on average at $180 \mathrm{~min}$, and it was seen that because it had a low amount of residual organic substance, it was possible to completely treat $25 \mathrm{mg} \mathrm{L}^{-1}$ of 2,4-D with a photocatalytic process. Thus, because the 15 min effluent value selected for the photocatalytic treatment (average COD amount: $\quad 47.5 \pm 0.71 \mathrm{mg} \mathrm{L}^{-1}$ ) included a sufficient amount of waste substance for a combined photocatalytic and biological treatment in that time, the similarity of treating it with a hybrid method was seen [29].

\subsection{Biological treatment performance on $2,4-D$ degradation}

To optimize efficiency, it is very important to determine the optimum time for processes where photodegradation and biodegradation are present together. If the photolysis time is too low, biodegradation will be inefficient because the pollutant will not be biodegradable enough. If it is too long, the process will not be economical because of the high cost of the photolysis process [30]. Recent research, including this study, has been carried out on biodegradation using mixed microbial mixtures (without using pure cultures) to mimic real conditions and maintain microbial activity over a wider range of conditions that will affect the rate of biodegradation $[8,9]$.

Although $25 \mathrm{mg} \mathrm{L}^{-1}$ 2,4-D was obtained as an optimum 2,4-D concentration at photocatalytic process, $50 \mathrm{mg} \mathrm{L}^{-1}$ of 2,4-D concentration was selected to degrade in biological reactor system in order to increase the organic pollutant concentration for microbial degradation. The change in removal efficiency of $2,4-D$ at the beginning and at day 4 was $9-87 \%$ at $\mathrm{P}-\mathrm{B}$ reactor outlet, and it was $5-42 \%$ and $4-38 \%$ for the NA-BR and A-BR reactors, respectively. While the microbial community can degrade, on average, $40 \%$ of $2,4-\mathrm{D}$ in $50 \mathrm{mg} \mathrm{L}^{-1}$ in $5760 \mathrm{~min}$, a lag phase is observed for longer than $1440 \mathrm{~min}$ in both aerated and non-aerated reactors 


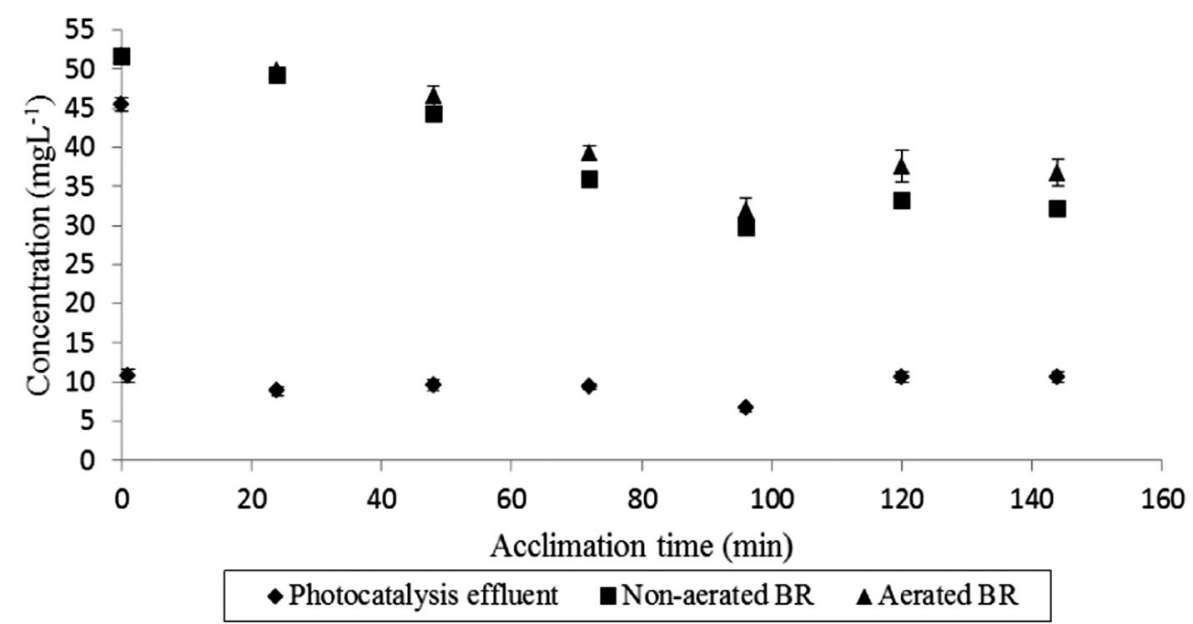

Figure 3. Time-dependent 2,4-D degradation by 3 different bioreactors non-aerated bioreactor (NA-BR), $\mathbf{\Delta}$ aerated bioreactor (A-BR))

(Figure 3). However, in the photobiolysis reactor, it is seen that there is a phase transition from the lag phase to the log phase in less than $60 \mathrm{~min}, 79.12 \pm 1.77 \%$ of herbicide removal is observed at the end of $60 \mathrm{~min}$, and $87.14 \pm 0.75 \%$ at the end of $5760 \mathrm{~min}$ (Figure 3). At the same time, all reactors could reach the stationary phase at the end of $5760 \mathrm{~min}$. In the photocatalysis experiment, 2,4-D degradation around $55 \%$ was obtained from 25 to $11.43 \mathrm{mg} \mathrm{L}^{-1}$ after $15 \mathrm{~min}$. Also, the initial 2,4-D concentration ( $50 \mathrm{mg} \mathrm{L}^{-1}$ ) was decreased to $45 \mathrm{mg} \mathrm{L}^{-1}$ after $15 \mathrm{~min}$ of photocatalysis, and further decreased to $10.79 \mathrm{mg} \mathrm{L}^{-1}$ after $60 \mathrm{~min}$ with biological treatment. This means, when the initial pollutant concentration increased, apparent rate constant $\left(k_{a p}\right)$ might decrease from $0.0441 \mathrm{~min}^{-1}$ at $25 \mathrm{mg} \mathrm{L}^{-1}$ to $0.0214 \mathrm{~min}^{-1}$ at $50 \mathrm{mg} \mathrm{L}^{-1}$. In the study, the initial 2,4D concentration $\left(50 \mathrm{mg} \mathrm{L}^{-1}\right)$ decreased to $45 \mathrm{mg} \mathrm{L}^{-1}$ after $15 \mathrm{~min}$ of photocatalysis, and further decreased to $10.79 \mathrm{mg} \mathrm{L}^{-1}$ after $60 \mathrm{~min}$ with biological treatment. Similarly, according to a study by Yahiat et al. [16], the concentration decreased to $12 \mathrm{mg} \mathrm{L}^{-1}$ because of a photocatalysis process with $85 \mathrm{mg} \mathrm{L}^{-1}$ of cyproconazole fungicide, which in turn increased its biodegradability. In this study, a $50 \mathrm{mg} \mathrm{L}^{-1}$ concentration for A-BR and NA-BR at the end of 2880 min did not have a significant toxic effect on the microbial population of 2,4-D. The low amount of 2,4-D removal obtained for A-BR and NA-BR, using direct biological oxidation, reveals the necessity of pre-treatment with photocatalysis before applying the biological treatment. Similarly, Yahiat et al. [16] indicated that $85 \mathrm{mg} \mathrm{L}^{-1}$ of cyproconazole fungicide only started to be consumed at the end of $3600 \mathrm{~min}$ in an environment including both glucose and ammonium, and a significant amount of growth was recorded in the growth phase (log phase) at the end of $3600 \mathrm{~min}$.
This phenomenon revealed that ammonium and glucose provide a carbon and nitrogen source for growth. Consumption of the pollutant at the end of 3600 min confirmed that this substance was used as an energy source in the stationary growth phase. Accordingly, the observed growth showed that this concentration did not have a toxic effect on $P$. fluorescens cells. The microbial lag phase time was shortened with a photochemical pre-treatment process, and the amount of organic macro-pollutants having high biodegradability - which can be degraded by microorganisms - was decreased. The reason for this can be the oxidation of the benzene ring before its separation in the biodegradation mechanism of 2,4-D [8]. Furthermore, as a result of $15 \mathrm{~min}$ photocatalysis of a $50 \mathrm{mg} \mathrm{L}^{-1}$ concentration of 2,4-D, $5 \mathrm{mg} \mathrm{L}^{-1}$ of it transformed into easily degradable byproducts and thus the biomass of the community increased; the remaining $45 \mathrm{mg} \mathrm{L}^{-1}$ enabled the formation of a high amount of digestive enzyme that can accelerate the biodegradation of 2,4-D [8].

However, since the amount of electricity consumed during photocatalytic process was also important in terms of cost, it was of great importance to carry out the biological treatment by limiting the photocatalytic process time to a minimum. In this study, the total cost was 247.59 USD kg ${ }^{-1}$ (881.56 TRY kg ${ }^{-1}$ ) in the biological treatment system, where a 15 -min pre-photocatalytic treatment was applied, and then $50 \mathrm{mg} \mathrm{L}^{-1}$ of 2,4-D was removed after applying a $5760 \mathrm{~min}$ aerated process, while the total cost for the $\mathrm{UV} / \mathrm{TiO}_{2}$ photocatalysis process for $180 \mathrm{~min}$ - where a maximum amount of removal was observed for $50 \mathrm{mg} \mathrm{L}^{-1}$ of 2,4-D - was 723.86 USD kg $^{-1}$ (2579.17 TRY kg ${ }^{-1}$ ), indicating that the cost was approximately three times as much. With the hybrid system, $90 \%$ of the 2,4-D herbicide could be 


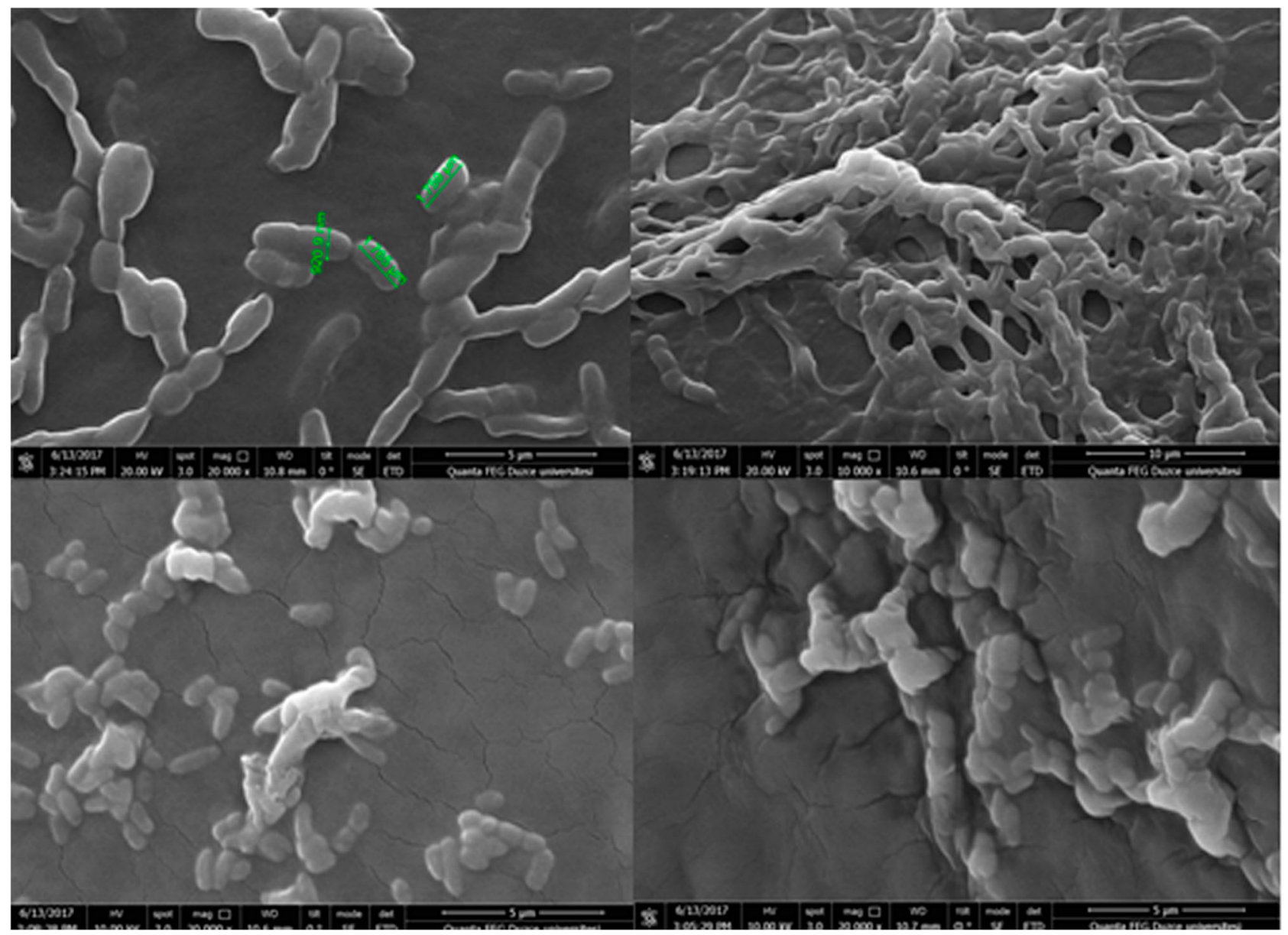

Figure 4. SEM image of rod biofilm bacteria obtained from biological reactors.

removed and organic pollutant removal was achieved at a lower cost in a shorter time than with the photocatalytic system.

Bioreactors, where immobilized cells are present, are usually the most efficient way to treat organic pollutants with biological treatment because biofilm processes are less sensitive to toxic substances than suspended processes [31]. Figure 4 shows the SEM image of the biofilm community while Figure 5 shows the elemental analysis of the microbial community performed by Energy Dispersive X-Ray Spectroscopy (EDS) analysis. Microorganism cells are composed of $50 \%$ (by weight) carbon $(\mathrm{C}), 14 \%$ nitrogen $(\mathrm{N})$ and the remaining amount is sulphur (S), phosphorus (P) and trace elements ( $\mathrm{Ca}, \mathrm{Mg}, \mathrm{K}, \mathrm{Na}, \mathrm{Fe}, \mathrm{Cu}, \mathrm{Zn}$ and etc.) [32]. According to the EDS analyses in Figure 5, the elemental analysis that indicates the presence of the microbial community was shown. Moreover, according to the EDS analysis, the elements of the 2,4-D salt $\left(\mathrm{C}_{10} \mathrm{H}_{13} \mathrm{Cl}_{2} \mathrm{NO}_{3}\right)$ in the adsorption onto the $\mathrm{TiO}_{2}$ catalyst are seen at the EDS peaks.

\subsection{Biological treatment performance on 2,4-D mineralization}

Evaluating chemical and biological treatment efficiencies, the maximum COD removal efficiency for 2,4-D reached $62.47 \pm 0.70 \%$ after 210 min with $1.5 \mathrm{~g} \mathrm{~L}^{-1}$ of $\mathrm{TiO}_{2}$ and UVA irradiation (Figure 6). When COD removal efficiencies in aerated and non-aerated biological reactors were examined, both reactors reached $78 \%$ after $5760 \mathrm{~min}$, while in the aerated biological reactor, the COD removal efficiency was higher than that in the non-aerated reactor. Moreover, the COD removal was $67.75 \pm 1.05 \%$ after $2880 \mathrm{~min}$ in the aerated reactor, while it was 49.71 $\pm 0.33 \%$ after $2880 \mathrm{~min}$ in the non-aerated biological reactor. Accordingly, it was verified that biological processes are slower than chemical processes and require longer times to reach the same removal efficiency as photocatalytic treatment [33]. Ballesteros-Martín et al. [9] reported that $31 \%$ of dissolved organic carbon (DOC) was removed in 140 min by the photo-Fenton reaction. Within $300 \mathrm{~min}, 90 \%$ DOC removal was achieved with 


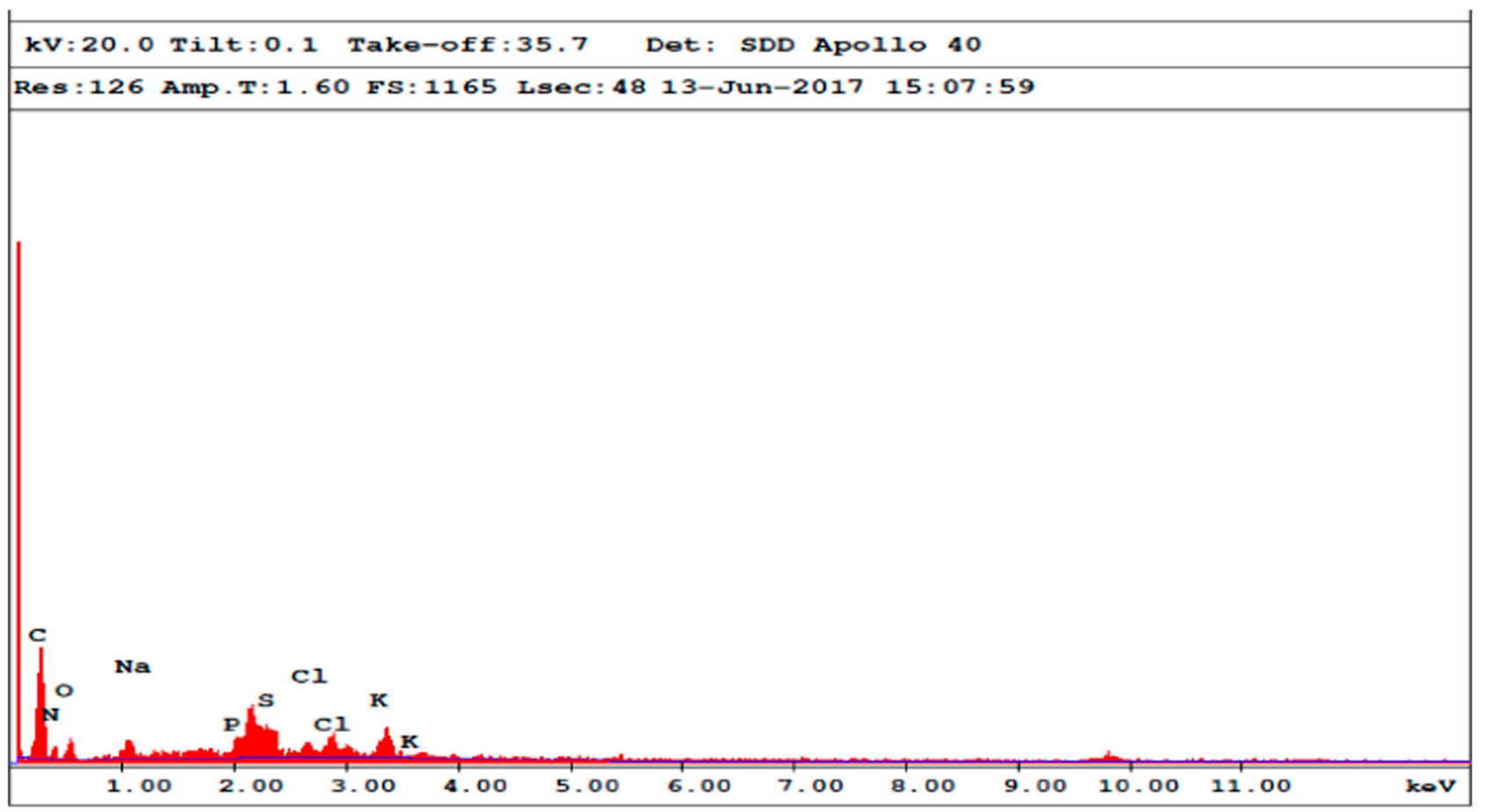

\begin{tabular}{|c|c|c|c|c|c|c|}
\hline Element & we 8 & At \& & K-Ratio & $\mathrm{z}$ & A & $\mathrm{F}$ \\
\hline C $\mathrm{K}$ & 56.17 & 66.92 & 0.1628 & 1.0184 & 0.2845 & 1.0002 \\
\hline $\mathrm{N} \mathrm{K}$ & 14.43 & 14.74 & 0.0149 & 1.0095 & 0.1025 & 1.0002 \\
\hline $0 \mathrm{~K}$ & 11.26 & 10.07 & 0.0158 & 1.0015 & 0.1401 & 1.0001 \\
\hline $\mathrm{NaK}$ & 3.48 & 2.17 & 0.0155 & 0.9376 & 0.4744 & 1.0008 \\
\hline $\mathrm{P} \mathrm{K}$ & 2.77 & 1.28 & 0.0241 & 0.9221 & 0.9336 & 1.0090 \\
\hline & 4.69 & 2.09 & 0.0423 & 0.9404 & 0.9527 & 1.0067 \\
\hline $\mathrm{ClK}$ & 2.59 & 1.04 & 0.0222 & 0.9000 & 0.9475 & 1.0056 \\
\hline K K & 4.62 & 1.69 & 0.0412 & 0.9082 & 0.9835 & 1.0000 \\
\hline Total & 100.00 & 100.00 & & & & \\
\hline
\end{tabular}

Figure 5. EDX graph and elemental composition (\%) of the biofilm.

the biologically active sludge process. A total of 200 $\mathrm{mg} \mathrm{L}^{-1}$ dimethoate, oxydemethon-methyl, carbaryl and methidathion pesticide mixture was removed with the combined system within 420 min.

With the, a maximum of $88.87 \pm 0.12 \%$ COD removal was obtained after $5760 \mathrm{~min}$. In this study, with the P-B system, a maximum of $88.87 \pm 0.12 \%$ COD removal was obtained after 5760 min (Figure 6). In addition, the total COD removal was $88.87 \%$ with the combined system; it was $18.31 \%$ for the first 15 min by photocatalytic treatment, and it was $70.56 \%$ after $5760 \mathrm{~min}$ (Figure 7). Fontmorin et al. [28] treated the commercial

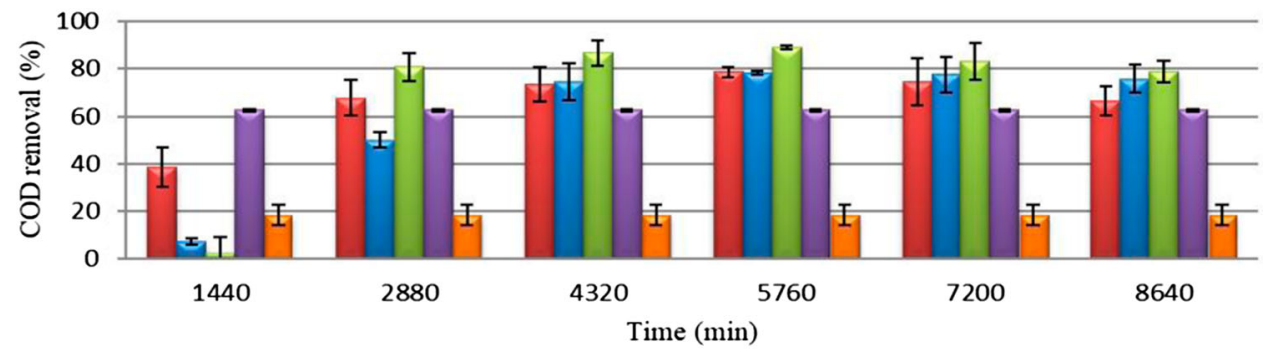

$\square \mathrm{A}-\mathrm{BR} \square \mathrm{NA}-\mathrm{BR} \square \mathrm{P} \& \mathrm{~B} \square \mathrm{P}(210 \mathrm{~min}) \square \mathrm{P}(15 \mathrm{~min})$

Figure 6. COD \% removal for different biological reactors (A-BR: aerated biological reactor, NA-BR: non-aerated biological reactor, P\&B: photobiocatalysis reactor, P (210 min): 210 min-photocatalysis, P (15 min): 15 min-photocatalysis. 


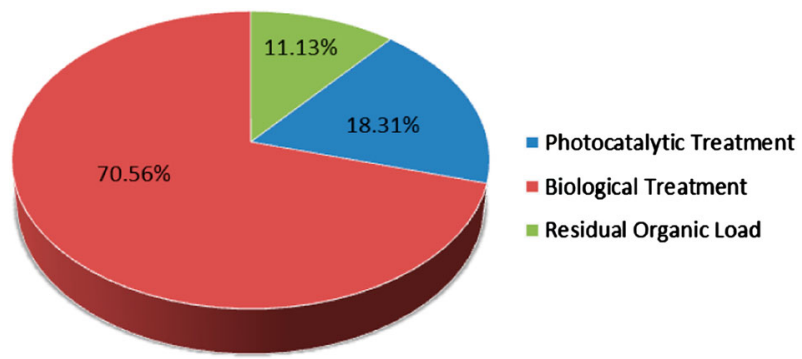

Figure 7. Mineralization efficiency obtained by combined system.

2,4-D herbicide (U46D ${ }^{\circledR}$ ) by a combined electrochemical and activated sludge method, and the mineralization of $\mathrm{U}_{46 \mathrm{D}^{\circledR}}$ (100 $\mathrm{mg} \mathrm{L}^{-1}$ of 2,4-D) was limited without any pre-treatment after 6 days, while they obtained $33.7 \%$ DOC removal after 8 days. In the $\mathrm{U}^{46 \mathrm{D}^{\circledR}}$ herbicide exposed to electrochemical pre-treatment, $63.7 \%$ DOC was observed up to 5 days, but it could not reach total mineralization (72.1\%). With the combined system, $82.1 \%$ mineralization was obtained.

\subsection{MALDI-TOF-MS identification in biological reactors}

The aim was to determine if the dominant microbial species in the biological reactor, which fed the photoreactor output, was greater than other biological reactors, and determine whether microbial diversity was affected by the performance of the reactor [17]. In total, 13 isolates were identified by MALDI-TOF-TOF/ MS, including four in the input activated sludge sample fed into the biological reactors, three in the sample obtained from the aerated biological reactor, two in the sample obtained from the NA-BR, and four in the biological reactant fed to the exposed water subjected to photocatalytic pre-treatment. Because of inoculation on PCA medium followed by a $2880 \mathrm{~min}$ incubation period, dominant colonies with different morphologies were obtained by passive colonization techniques and pure cultures were inoculated on separate petri dishes by an aseptic technique and reproduced after 1440 min incubation before being identified by the MALDI-TOF-TOF/MS device.

Bacillus subtilis, Bacillus simplex, Ralstonia pickettii, and Acinetobacter towneri bacteria isolates were detected with the highest accuracy in the samples obtained from the influent wastewater fed to all three biological reactors (Figure S1). It was reported by Kim et al. [34] R. pickettii (Pseudomonas pickettii) can degrade 2,4-D. MarrónMontiel et al. [35] determined that, for the first time, Acinetobacter bacteria could degrade 2,4-D herbicide. Table 1 shows microorganism species identified according to reactor type, as well as their characteristics. As can be seen from the raw MALDI-TOF-TOF/MS profiles in Figure $\mathrm{S} 1$ to 4 , densities and numbers of mass signals show differences. MALDI-TOF-TOF/MS profiles were compared with the reference spectrum in the BioTyper database and the similarities were identified by BioTyper Log (score). The colour panels are (A-M) rod spectra, they were matched with the experimental MALDI profiles of the strains (the colour panel on top), and with reference MALDI profiles (the blue panel at the bottom). Green, yellow and red rods on the colour panel indicate perfect, moderate and low peak match (density and $\mathrm{m} / \mathrm{z}$ value) between experimental results and the reference MALDI database, respectively [18]. Matching pairs are evaluated by Log (score). At the same time, as a result of a comparison of the peaks obtained and the database, the first ten samples are rated from the highest accuracy (green) to the least accuracy (red) (Figures S1-S4). The Log (score) is calculated by the peak weight representing the correlation factor related to the number of matched peaks, total peak number, originality of species and the densities of matched peaks [36]. For B. subtilis, accurate identification at kind level could be made with the DT method, while accurate identification at species level

Table 1. Microorganism species identified in the biological reactors and their characteristics.

\begin{tabular}{|c|c|c|}
\hline Biological reactor & $\begin{array}{l}\text { Microorganism } \\
\text { species }\end{array}$ & Microorganism characteristics \\
\hline $\begin{array}{l}\text { Biological reactor inlet } \\
\text { water sample }\end{array}$ & $\begin{array}{l}\text { B. subtilis } \\
\text { R. pickettii } \\
\text { B. simplex } \\
\text { A. towneri }\end{array}$ & $\begin{array}{l}\text { Gram (+), Basil, strict aerobe or facultative anaerobe } \\
\text { Gram (-), Basil, strict aerobe } \\
\text { Gram (+), Basil, strict aerobe or facultative anaerobe } \\
\text { Gram (-), Basil, strict aerobe }\end{array}$ \\
\hline $\begin{array}{l}\text { Aerated biological } \\
\text { reactor sample }\end{array}$ & $\begin{array}{l}\text { S. acidaminiphila } \\
\text { E. coli } \\
\text { R. ornithinolytica }\end{array}$ & $\begin{array}{l}\text { Gram (-), Basil, strict aerobe, belonging to the Xanthomonadaceae family and a Stenotrophomonas sub-species } \\
\text { Gram (-), Basil, Enterobacter, Facultative anaerobe } \\
\text { Gram (-), aerobe, an Enterobacter species of the Klebsiella group }\end{array}$ \\
\hline $\begin{array}{l}\text { Non-aerated biological } \\
\text { reactor sample }\end{array}$ & $\begin{array}{l}\text { K. pneumoniae } \\
\text { C. freundii }\end{array}$ & $\begin{array}{l}\text { Gram }(-) \text {, anaerobe, a fermenting bacteria in the Enterobacter family } \\
\text { Gram }(-) \text {, Facultative anaerobe, in the Enterobacter family, Basil }\end{array}$ \\
\hline $\begin{array}{l}\text { Biological reactor } \\
\text { sample subjected to } \\
\text { photocatalytic pre- } \\
\text { treatment }\end{array}$ & $\begin{array}{l}\text { B. subtilis } \\
\text { C. freundii } \\
\text { A. eucrenophila } \\
\text { S. multivorum }\end{array}$ & $\begin{array}{l}\text { Gram (+), Basil, strict aerobe or facultative anaerobe } \\
\text { Gram (-), Facultative anaerobe, in the Enterobacter family, Basil } \\
\text { Gram (-), a kind of aeromonas, facultative anaerobe, Basil } \\
\text { Gram (-), a species of Flavobacterium, aerobe }\end{array}$ \\
\hline
\end{tabular}


could be made with the formic acid (FA) method. With the DT method, $R$. pickettii could be identified at species level. B. simplex and A. towneri could be identified at kind level, while a successful identification could not be made using the FA method.In the A-BR system, Stenotrophomonas acidaminiphila, Escherichia coli, Raoultella ornithinolytica bacteria were identified as dominant (Figure S2). Samir et al. [8] showed that Stenotrophomonas maltophilia species could biologically degrade the 2,4-D herbicide.

In the NA-BR, Klebsiella pneumoniae and Citrobacter freundii were identified as dominant. Marrón-Montiel et al. [35] determined that for the first time Klebsiella bacteria played a role in degrading 2,4-D herbicide.

In biological reactor samples subjected to photocatalysis pre-treatment, $B$. subtilis, C. freundii, Aeromonas eucrenophila and Sphingobacterium multivorum bacteria species were observed to be dominant (Figure S4, Table 1). Furthermore, it is known that Sphingobacterium species are among those that can degrade 2,4-D [37] (Figure S4). Liberatore et al. [14] identified Sphingobacterium in a bacterial community while removing Dazomet and Fenamiphos pesticides using a combined chemical and biological treatment, because of examining microflora in the biological treatment. Kim et al. [38] reported that Aeromonas sp. species was used in the biodegradation of 2,4-D herbicide. Sandoval-Carrasco et al. [39] identified five different bacteria isolates in the removal of 2,4-D herbicide: Aeromonas, Acidovorax, Chryseobacterium, Variovorax and Xanthobacter.

The 2,4-D is firstly degraded by Achromobacter, Bordetella, Xanthobacter, Streptomyces, Aspergillus, Corynebacterium, Nocardia, Achromobacter, Alcaligenes, Arthrobacter, Flavobacterium and Pseudomonas. The members of the last four groups use the 2,4-D as a single carbon source [40]. Accordingly, in this study, the A. eucrenophila, S. acidaminiphila, R. pickettii, S. multivorum and A. towneri species identified with high accuracy played important roles in the degradation of 2,4-D.

According to the results, although the microbial species developed in each reactor differ from each other, $C$. freundii was not observed to be dominant in the aerated reactor and influent, but it was seen in the biological treatment of the wastewater subjected to photocatalytic pre-treatment by a non-aerated biological reactor. B. subtilis was observed in both influent samples and the biological treatment system of the wastewater subjected to photocatalytic pre-treatment.The observation of different bacterial species in three different reactor systems can be attributed to the reactor characteristics of microbial ecologies in bioreactors [21].

According to Goel et al. [16], the addition of glucose is important to achieve complete mineralization of toxic compounds. Similar results obtained from the combined system of MCP at different glucose concentrations $(0,1$ and $2 \mathrm{~g} \mathrm{~L}^{-1}$ ) after 3600 min show completed TOC removal, and the addition of a biogenic substrate accelerated the growth of microorganisms. Accordingly, in this study after 4 days, it is thought that microbial growth was inhibited by biologically toxic substances formed due to the degradation of the 2,4-D and the herbicide mineralization and degradation decreased after $5760 \mathrm{~min}$ (depending on microbial growth inhibition) before becoming stable. As a result, it is predicted that after $5760 \mathrm{~min}$, mineralization can increase to $90 \%$ by improving the microbial growth with the addition of a glucose substrate.

\section{Conclusions}

The combination of photocatalytic and biological oxidation was demonstrated to be an effective treatment for rapid herbicide degradation $(80.89 \pm 0.81 \%$ COD and $81.36 \pm$ $1.37 \%$ 2,4-D removal were achieved after 2 days) in water containing $50 \mathrm{mg} \mathrm{L}^{-1}$ of herbicide. However, the COD removal was $67.75 \pm 1.05 \%$ after 2 days in the aerated reactor, while it was $49.71 \pm 0.33 \%$ after $48 \mathrm{~h}$ in the nonaerated biological reactor. This means, biodegradation alone did not mineralize the COD by more than $68 \%$. Thus, the concept and benefit of coupling photocatalysis and biodegradation were demonstrated in this study. According to MALDI-TOF-TOF/MS results, the microbial species developed in each reactor show differences. Furthermore, that various bacterial species were observed in three different reactors may be due to the reactor characteristics of microbial ecologies in bioreactors.

\section{Acknowledgements}

The authors would like to thank TUBITAK for the Ph.D. Dissertation Grant given to Gamze Dogdu Okcu within the 2211/A National Doctoral Scholarship Program.

\section{Disclosure statement}

No potential conflict of interest was reported by the authors.

\section{Funding}

This study was financially supported by AIBU Scientific Research Projects, Project Number: 2016.09.02.1033.

\section{References}

[1] Vishnuganth MA, Neelancherry R, Kumar $M$, et al. Carbofuran removal in continuous-photocatalytic reactor: reactor optimization, rate-constant determination and carbofuran degradation pathway analysis. J Environ Sci. Health B. 2017;52:353-360. 
[2] United States Prevention Agency (EPA). Prevention, pesticides and toxic substances (7508C). Reregistration eligibility decision for 2,4-d; 2005. [cited 2017 Nov 10]. Available from https://archive.epa.gov/pesticides/reregistration/web/pdf/ 24d_red.pdf.

[3] Quan X, Ma J, Xiong W, et al. Bioaugmentation of halfmatured granular sludge with special microbial culture promoted establishment of 2,4-dichlorophenoxyacetic acid degrading aerobic granules. Bioprocess Biosyst Eng. 2015;38:1081-1090.

[4] Mekonen S, Argaw R, Simanesew A, et al. Chemosphere pesticide residues in drinking water and associated risk to consumers in Ethiopia. Chemosphere. 2016;162:252-260.

[5] US EPA. Health advisory: 2,4-dichlorophenoxyacetic acid. Washington (DC): Environmental Protection Agency; 1987.

[6] Turkish Republic official Gazette Turkish regulation on human consumption water, Part four, Appendix-1, chemical parameters (25730), 17.02.2005, 19.

[7] USEPA, Ground water and drinking water regulation; 2017. [cited 2017 May 15]. Available from https://www. epa.gov/groundwater-and-drinking-water/nationalprimary-drinking-water-regulations.

[8] Samir R, Essam T, Ragab Y, et al. Enhanced photocatalyticbiological degradation of 2,4 dichlorophenoxyacetic acid. Bull Fac Pharm Cairo Univ. 2015;53:77-82.

[9] Ballesteros Martin MM, Sanchez Perez JA, Casas Lopez JL, et al. Degradation of a four-pesticide mixture by combined photo-Fenton and biological oxidation. Water Res. 2009;43:653-660.

[10] Oh $\mathrm{KH}$, Tuovinen $\mathrm{OH}$. Bacterial degradation of phenoxy herbicide mixtures 2,4-D and MCPP. Bull Environ Contam Toxicol. 1991;47:222-229.

[11] Cardoso JC, Bessegato GG, Zanoni MVB. Efficiency comparison of ozonation, photolysis, photocatalysis and photoelectrocatalysis methods in real textile wastewater decolorization. Water Res. 2016;98:39-46.

[12] Suryaman D, Hasegawa K. Biological and photocatalytic treatment integrated with separation and reuse of titanium dioxide on the removal of chlorophenols in tap water. J Hazard Mater. 2010;183:490-496.

[13] Oller I, Malato S, Sánchez-Pérez JA. Combination of advanced oxidation processes and biological treatments for wastewater decontamination-a review. Sci Total Environ. 2011;409:4141-4166.

[14] Liberatore L, Bressan M, Belli C, et al. Chemical and biological combined treatments for the removal of pesticides from wastewaters. Water Air Soil Pollut. 2012;223:4751-4759.

[15] Loverira EL, Fiol PS, Senn A, et al. $\mathrm{TiO}_{2}$-photocatalytic treatment coupled with biological systems for the elamination of benzalkonium chloride in water. Sep Purif Technol. 2012;91:108-116.

[16] Yahiat S, Fourcade F, Brosillon S, et al. Photocatalysis as a pre-treatment prior to a biological degradation of cyproconazole. Desalination. 2011;281:61-67.

[17] Marsolek MD, Kirisits M, Gray KA, et al. Coupled photocatalytic-biodegradation of 2,4,5-trichlorophenol: effects of photolytic and photocatalytic effluent composition on bioreactor process performance, community diversity, and resistance and resilience to perturbation. Water Res. 2014;50:59-69.

[18] Nacef $M$, Chevalier $M$, Chollet $S$, et al. MALDI-TOF mass spectrometry for the identification of lactic acid bacteria isolated from a French cheese: The maroilles. Int J Food Microbiol. 2017;247:2-8.

[19] Haigh J, Degun A, Eydmann M, et al. Improved performance of bacterium and yeast identification by a commercial matrix-assisted laser desorption ionization-time of flight mass spectrometry system in the clinical microbiology laboratory. J Clin Microbiol. 2011;49:3441.

[20] Schulthess B, Brodner K, Bloemberg GV, et al. Identification of gram-positive cocci by use of matrixassisted laser desorption ionization-time of flight mass spectrometry: comparison of different preparation methods and implementation of a practical algorithm for routine diagnostics. J Clin Microbiol. 2013;51:1834-1840.

[21] Djebbar K, Zertal A, Sehili T. Photocatalytic degradation of 2,4-dichlorophenoxyacetic acid and 4-chloro-2-methylphenoxyacetic acid in water by using $\mathrm{TiO}_{2}$. Environ Technol. 2006;27:1191-1197.

[22] Amalraj A, Pius A. Photocatalytic degradation of monocrotophos and chlorpyrifos in aqueous solution using $\mathrm{TiO}_{2}$ and UV irradiation. J Water Proc Eng. 2015;7:94-101.

[23] Diaz E, Cebrian M, Bahamonde A, et al. Degradation of organochlorinated pollutants in water by catalytic hydrodechlorination and photocatalysis. Catal Today. 2016;266:168-174.

[24] Singh HK, Muneer M. Photodegradation of a herbicide derivative, 2,4-dichlorophenoxy acetic acid in aqueous suspensions of titanium dioxide. Res Chem Intermed. 2004;30:317-329.

[25] Deletze E, Antoniadis A, Kitsiou V, et al. Photocatalytic treatment of colored wastewater from medical laboratories: photodegradation of nuclear fast red. Desalin Water Treat. 2016;57:18897-18905.

[26] Bouafia-Chergui $\mathrm{S}$, Zemmouri $\mathrm{H}$, Chabani $\mathrm{M}$, et al. $\mathrm{TiO}_{2}-$ photocatalyzes degradation of tetracycline: kinetic study, adsorption isotherms, mineralization and toxicity reduction. Desalin Water Treat. 2016;57:16670-16677.

[27] Fourcade F, Yahiat S, Elandaloussi K, et al. Relevance of photocatalysis prior to biological treatment of organic pollutants-selection criteria. Chem Eng Technol. 2012;35:238-246.

[28] Fontmorin JM, Fourcade F, Geneste F, et al. Combined process for 2,4-dichlorophenoxyacetic acid treatmentcoupling of an electrochemical system with a biological treatment. Biochem Eng. J. 2013;70:17-22.

[29] Khenniche L, Favier L, Bouzaza A, et al. Photocataytic degradation of bezacryl yellow in batch reactors- feasibility of the combination of photocatalysis and a biological treatment. Environ Technol. 2015;36:1-10.

[30] Suryaman D, Hasegawa K, Kagaya S. Combined biological and photocatalytic treatment for the mineralization of phenol in water. Chemosphere. 2006;65:2502-2506.

[31] Perron N, Welander U. Degradation of phenol and cresol at low temperatures using a suspended-carrier biofilm process. Chemosphere. 2004;55:45-50.

[32] Heldal M, Norland S, Fagerbakke KM, et al. The elemental composition of bacteria: a signature of growth conditions? Mar Pollut Bull. 1996;33:3-9.

[33] Yeber M, Paul E, Soto C. Chemical and biological treatments to clean oily wastewater: optimization of the photocatalytic process using experimental design. Desalin Water Treat. 2012;47:295-299. 
[34] Kim DU, Kim MS, Lim JS, et al. Widespread occurrence of the tfd-Il genes in soilbacteria revealed by nucleotide sequenceanalysis of 2,4-dichlorophenoxyacetic acid degradative plasmids pDB1 and p712. Plasmid. 2013;69:243-248.

[35] Marrón-Montiel E, Ruiz-Ordaz N, Rubio-Granados C, et al. 2,4-D-degrading bacterial consortium isolation, kinetic characterization in batch and continuous culture and application for bioaugmenting an activated sludge microbial community. Process Biochem. 2006;41:1521-1528.

[36] Cherkaoui A, Hibbs J, Emonet S, et al. Comparison of two matrix-assisted laser desorption ionization-time of flight mass spectrometry methods with conventional phenotypic identification for routine identification of bacteria to the species level. J Clin Microbiol. 2010;48:1169-1175.

[37] Baelum J, Jacobsen CS, Holben WE. Comparison of $16 \mathrm{~S}$ rRNA gene phylogeny and functional tfdA gene distribution in thirty-one different 2,4-dichlorophenoxyacetic acid and 4-chloro-2-methylphenoxyacetic acid degraders. Syst Appl Microbiol. 2010;33:67-70.

[38] Kim B, Han M, Cho S, et al. Statistical optimization for biodegradation of 2,4-dichlorophenoxyacetic acid by soil isolated bacterium. Korean J Microbiol Biotechnol. 2003;31:83-89.

[39] Sandoval-Carrasco CA, Ahuatzi-Chacón D, Galíndez-Mayer $\mathrm{J}$, et al. Biodegradation of a mixture of the herbicides ametryn, and 2,4-D, chlorophenoxyacetic acid (2,4-D) in a compartmentalized biofilm reactor. Bioresour Technol. 2013;145:33-36.

[40] Ka JO, Holben WE, Tiedje JM. Genetic and phenotypic diversity of 2,4-dichlorophenoxyacetic acid (2,4-D)degrading bacteria isolated from 2,4-D-treated field soils. J Appl Environ Microbiol. 1994;60:1106-1115. 